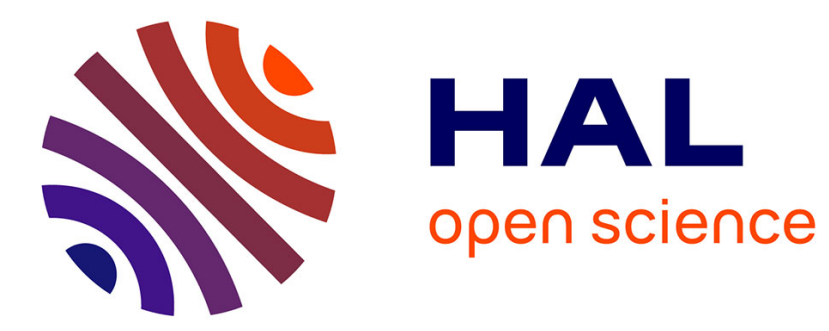

\title{
Myositis-specific autoantibodies, a cornerstone in immune-mediated necrotizing myopathy
}

Céline Anquetil, Olivier Boyer, Nadège Wesner, Olivier Benveniste, Yves Allenbach

\section{- To cite this version:}

Céline Anquetil, Olivier Boyer, Nadège Wesner, Olivier Benveniste, Yves Allenbach. Myositis-specific autoantibodies, a cornerstone in immune-mediated necrotizing myopathy. Autoimmunity Reviews, 2019, 18 (3), pp.223-230. 10.1016/j.autrev.2018.09.008 . hal-02377517

\section{HAL Id: hal-02377517 https://hal.science/hal-02377517}

Submitted on 22 Oct 2021

HAL is a multi-disciplinary open access archive for the deposit and dissemination of scientific research documents, whether they are published or not. The documents may come from teaching and research institutions in France or abroad, or from public or private research centers.
L'archive ouverte pluridisciplinaire HAL, est destinée au dépôt et à la diffusion de documents scientifiques de niveau recherche, publiés ou non, émanant des établissements d'enseignement et de recherche français ou étrangers, des laboratoires publics ou privés.

\section{(ㄷ)(1) $\$$}

Distributed under a Creative Commons Attribution - NonCommerciall 4.0 International 


\section{Review: Myositis-specific autoantibodies, a cornerstone in immune-mediated necrotizing myopathy}

Céline Anquetil ${ }^{1,2}$, Olivier Boyer ${ }^{3}$, Nadège Wesner ${ }^{1,2}$, Olivier Benveniste ${ }^{1,2}$, Yves Allenbach ${ }^{1,2}$

1. Department of Internal Medicine and Clinical Immunlogy, Sorbonne Universités, PitiéSalpêtrière University Hospital, Paris, France.

2. Institut National de la Santé et de la Recherche Médicale, Association Institut de Myologie, Centre de Recherche en Myologie, UMRS974, Paris, France.

3. Normandie University, UNIROUEN, IRIB, Inserm, U1234, Rouen University Hospital, Department of Immunology and Biotherapy, Rouen, France.

Corresponding author: Yves Allenbach, Department of Internal Medicine and Clinical Immunology, Sorbonne Universités, Pitié-Salpêtrière University Hospital, 82 boulevard de I'Hôpital, F-75013, Paris, France. yves.allenbach@aphp.fr

\section{Abstract}

Over the past few years, myositis-specific autoantibodies played an increasing role in the inflammatory idiopathic myositis definition. They became the critical immunological marker for immune-mediated necrotizing myopathy diagnosis (IMNM) since the paradigm switch from histological to serological criteria.

This review is focused on the key role of the anti-signal recognition particle (anti-SRP) and the anti-3-Hydroxy-3-MethylGlutaryl-Coenzyme A Reductase (anti-HMGCR) antibodies in immune-mediated necrotizing myopathy.

Anti-SRP and anti-HMGCR antibodies are robust diagnostic tools in case of both the classical subacute form and the slowly progressive form of IMNM that may mimic muscular dystrophy. Anti-SRP and anti-HMGCR patients share clinical, biological and histological features with some antibody-associated specificity. Anti-SRP patients harbour more severe muscle weakness and atrophy with severe muscle damage on magnetic resonance imaging study. Approximately $10-20 \%$ of anti-SRP patients develop extramuscular symptoms, especially lung interstitial disease. Conversely, anti-HMGCR patients are often associated with statin exposure. In both cases, patients have a poor outcome with frequent relapse and 
the use of combined immunotherapy. Of note, various data suggest a direct pathogenic role of these antibodies reinforcing the interest in targeted therapeutic strategy.

Keywords: immune-mediated necrotizing myopathy, autoantibodies, signal recognition particle, 3-hydroxy-3-methylglutaryl-coenzyme A reductase

\section{No disclosure}

Funding: This research did not receive any specific grant from funding agencies in the public, commercial, or not-for-profit sectors. 
Introduction

Over the past few years, idiopathic inflammatory myopathies have been deciphered into different subsets sharing specific clinical, biological, immunological and histological features. The identification of myositis-specific autoantibodies (MSA) helped refine classification and became a cornerstone of the diagnosis process. One subset of idiopathic inflammatory myopathy, the immune-mediated necrotizing myopathy (IMNM), is individualized based on the myopathological features: muscle fibres necrosis/regeneration and sparse inflammatory infiltrate [1].

The definition of this new entity, sometimes referred to as Necrotizing Autoimmune Myopathy in some earlier reports, follows a study reporting the pathological feature of anti-signal recognition particle (SRP) 'polymyositis'. In this study Miller et al. described for the first time this myopathological pattern [2]. Later, in addition to anti-SRP antibody, the anti-3-Hydroxy-3MethylGlutaryl-Coenzyme A Reductase (HMGCR) antibody was also specifically associated with IMNM [3,4]. Recently, a new classification of idiopathic inflammatory myopathies by unsupervised multiple correspondence analysis aggregates IMNM patients in an homogeneous and distinct cluster defined by high creatine kinase levels, necrotic fibers without inflammation on muscle biopsy and anti-SRP or anti-HMGCR antibodies [5].

Anti-SRP was found initially in human serum of one 'polymyositis' patient by RNA immunoprecipitation with K562 cell extracts [6]. Twenty years later, a second antibody against a 200/100-kd protein was discovered in a series of IMNM patients. Next, the target HMGCR was identified in part because the anti-200/100-kd antibody positive patients were frequently statin-exposed [4].

Since the first reports on IMNM, knowledge about its pathogenesis, clinical characteristics, histological patterns, treatment efficacy and prognosis has increased substantially. This review highlights the key role of anti-SRP and anti-HMGCR antibodies in IMNM. 


\section{Autoantibodies and pathogenesis}

\subsection{Description of antigenic targets}

Signal recognition particle is an intracellular ribonucleoprotein complex gathering six proteins (SRP9, SRP14, SRP19, SRP54, SRP68 and, SRP72) and a 7S RNA molecule. SRP is dedicated to target proteins to the endoplasmic reticulum, which is a highly conserved and ubiquitous system among many species. SRP targeting proteins to the endoplasmic reticulum can be described as a three-step process: first, SRP binds to the signal sequence of the ribosome nascent chain complex; then, it delays protein elongation; and third, SRP helps protein translocation through the protein-conducting channel by docking with the membrane-bound SRP receptor [7]. More precisely, the SRP54 subunit interacts with the signal sequence via its methionine-rich domain in the C-terminal region and with the SRP receptor via its central guanosine triphosphate (GTP)-binding domain [8]. An epitope mapping study found the autoantibodies binding to the SRP54 N-terminal or G-central region with no recognition of the C-terminal region [9]. Only $82 \%$ of anti-SRP patients develop autoantibodies against SRP54; other subunits of the SRP complex could also be the target of autoantibodies [10].

Regarding the isotype of anti-SRP, IgG1 is the most frequent subtype with more than $80 \%$ of patients' sera testing positive, followed by $\lg G 4$ antibodies and very rarely $\lg G 3$ (no $\lg G 2$ ); as for anti-HMGCR, only lgG1 is identified $[11,12]$. In vitro assays show the inhibitory effect of human anti-SRP antibodies on the SRP-dependent targeting pathway via the reduction of crosslinking between SRP54 and signal sequence [9].

HMGCR is the second recently identified antigenic target in IMNM. This enzyme is located in the endoplasmic reticulum and catalyses the reductive cleavage of HMG-CoA to mevalonate, 
which is the rate-limiting process in sterols and isoprenoids synthesis [13]. The HMGCR protein of 888 amino acids binds to the endoplasmic reticulum membrane through its $\mathrm{N}$ terminal region, and the C-terminal region contains the catalytic activity [14]. In 2010, amongst IMNM patients (based on pathological definition) without known autoantibodies, an antibody with specificity against a 200/100-kd protein was identified [15]. This protein was up-regulated after statin exposure and was identified as HMGCR, a key enzyme in the cholesterol metabolism pathway and the statin target [4]. A mapping study identified the Cterminal part as the epitope target [4]. The specific muscular deletion of HMGCR in a KO mouse model led to severe muscle damage and macrophage infiltration with the phenotype rescued by injection of mevalonate [16]. There is no KO mouse model available for SRP.

\subsection{Potential role of autoantibodies}

Understanding the pathogenesis of IMNM requires further investigation, but a growing set of data suggests the pathogenic involvement of autoantibodies.

In in vitro experiments on myotubes, incubation with anti-SRP antibodies, anti-HMGCR antibodies or total IgG from patients' plasmapheresis induced atrophy and was associated with increased expression of the transcription factors TRIM63/MURF1 and MAFbx, which are involved in the atrophy pathway. Muscle atrophy is one of the most important clinical and histological features of IMNM $[17,18]$. In addition, proinflammatory molecules (IL-6, TNF) and reactive oxygen species were enhanced while anti-inflammatory cytokines (IL-4 and IL-13) levels were reduced in the presence of purified total IgG from patients [19]. This decrease of IL-4 and IL-13 blocked myotubes formation by impairing myoblasts fusion; this phenotype was restored by the addition of those two cytokines [19]. On cultured myoblasts, surface staining after incubation with anti-SRP serum and complement was positive for SRP and C3c showing co-localization at the plasma membrane; this pattern was absent when anti-SRP negative control serum was used [20]. 
In ex vivo studies on muscle sections from anti-SRP patients, positive sarcolemmal staining for SRP and C3c was found in a few non-necrotic muscle fibres and in necrotic fibres [20]. Sarcolemmal staining for SRP and HMGCR was observed using both purified autoantibodies from patients and commercial antibodies on regenerative cells [17]. In the same experimental study, sarcolemmal deposits of C5b-9 (membrane attack complex) were identified with a scattered distribution in fascicles, deposits of $\mathrm{C} 1 \mathrm{q}$ and stains for $\lg \mathrm{G}$. These results altogether supported the hypothesis of activation of the classical pathway of complement in patients' muscle [17]. Conversely, muscle biopsies of dystrophic patients do not usually harbour sarcolemmal C5b-9 positive staining even if this may be observed in dysferlinopathy. [21].

The following observations suggest the pathogenic role of the antibodies: (i) in vitro effect of anti-SRP and anti-HMGCR purified IgG on myotubes formation, (ii) in vitro and ex vivo sarcolemmal deposits of complement classical pathway proteins (C1q, C3c, C5b-9), and (iii) the frequent lgG1 isotype (efficient trigger of complement classical pathway).

In vivo studies with passive transfer of autoantibodies or immunization with antigens in animal models are mandatory to deepen our understanding and confirm this theory. Different animal models were developed to study idiopathic inflammatory myopathies, in particular, immunological models using skeletal muscle tissue antigens like myosin [22]. Recently, an in vivo model demonstrated the pathogenic role of IgG from IMNM patients for the first time. Passive transfer of IgG from anti-SRP or anti-HMGCR positive patients was performed in C57/BI6 or Rag2 deficient or Complement 3 deficient mice. The muscle strength measured by grip test was significantly decreased after transfer of patient IgG. Moreover, histological analysis showed the presence of necrotic myofibres and C5b-9 deposits. Passive transfer in Complement 3 deficient mice induced a more severe decrease of muscle strength compared to wild type mice [23]. 
In addition, it remains to be clarified why muscular-specific autoimmune disease is associated with auto-antibodies targeting ubiquitous proteins.

2. Autoantibodies as a diagnostic tool

Anti-HMGCR and anti-SRP antibodies are fundamental tools to diagnose IMNM and have been recently recognized as diagnostic criteria [24-26].

\subsection{Frequency of autoantibodies}

Including all known MSA, $60 \%$ of patients with inflammatory idiopathic myopathies harboured autoantibodies in their sera [27]. Specifically, anti-SRP antibodies have been detected in 4$6 \%$ of patients in a European cohort and in $8-13 \%$ of patients in an Asian cohort $[25,27,28]$. Anti-HMGCR antibodies have been identified in $6 \%$ of patients with muscle symptoms in both an American cohort [4] and a European cohort [29]. In the subgroup of IMNM patients, up to $53 \%$ presented anti-SRP and up to $64 \%$ anti-HMGCR $[3,15,30,31]$, showing that a group of IMNM does not harbour known autoantibody. Of note, the presence of both anti-SRP and anti-HMGCR appeared to be very rare [32,33] and they were considered mutually exclusive. Association between Anti-HMGCR and other MSA is marginal; few reports described antiHMGCR and anti-Jo1, anti-SRP and anti-Jo1 or anti-SRP and anti-PL12 double positivity $[4,32,34,35]$.

\subsection{Diagnostic methods}

There is a paradigm switch underway from using histological criteria as the gold standard to using immunological tests. Now, the diagnosis can be established based on serodiagnostic tests without myopathological proof [24]. This change emphasizes the importance of sensitive and specific immunodiagnostic assays.

Several studies have compared the diagnostic accuracy of different immuno-assays. HMGCR was initially assessed by the labor-intensive immunoprecipitation assay, a method 
better suited for research than for routine use. A comparison of immunoprecipitation and enzyme-linked immunosorbent assay (ELISA) on anti-HMGCR patients, other diseases (including muscular and other autoimmune diseases) and healthy controls found ELISA 95.1\% sensitive and $100 \%$ specific [36]. Other techniques more adapted for routine have been develop to detect anti-HMGCR: chemiluminescent immunoassay (CIA) [37], addressable laser bead immunoassay (ALBIA) [12]. ALBIA testing of anti-HMGCR positive sera and negative controls compared to ELISA and CIA techniques showed qualitative agreements of $100 \%$ and significant correlation between techniques in two-to-two comparisons [29]. Interestingly, in anti-HMGCR positive patients, an indirect immunofluorescence characteristic pattern has been described by several teams on rat liver $[38,39]$. This specific pattern was not identified in anti-HMGCR negative patients suffering from other auto-immune diseases, nor in statin-exposed patients. These results showed a high level of concordance with ELISA (kappa=0.9) [38]. Indirect immunofluorescence is a routine test that may be useful to screen anti-HMGCR myopathy amongst statin-exposed patients.

Anti-SRP was initially detected by RNA immunoprecipitation; currently, ELISA, ALBIA and immunodot are commonly utilized to detect autoantibodies. ELISA was compared to the gold standard method and a high level of correlation was observed (kappa=0.94) [30]. The ELISA for anti-SRP is $88 \%$ sensitive and $100 \%$ specific [30]. Anti-SRP ALBIA was validated as a sensitive, specific and reproducible method [11]. A multiplex ALBIA was developed to screen anti-SRP and anti-HMGCR antibodies from one serum sample, and the multiplex ALBIA detected with the same sensitivity compared to the monoplex [12].

These tests are efficient but do present some pitfalls. Immunodot is only qualitative. The routine tests (ELISA, dot blot, ALBIA) to diagnose anti-SRP positive patients are based on the recognition of anti-SRP54 antibodies. Hence, there is a risk of false negative results due to this narrowed search $[10,11,30]$. In the case with a typical phenotype with a compatible histological pattern but no antibody, anti-SRP IMNM diagnosis should not be excluded and 
other methods should be applied. Immunoprecipitation may not be feasible in clinical practice; in that case, observation of a cytoplasmic dense fine speckled immunofluorescent pattern is helpful to the diagnosis. Conversely, false positive diagnosis may seldom occur with anti-HMGCR ELISA [40].

\subsection{Autoantibodies in clinical practice}

As mentioned above, IMNM diagnosis relies on a serological-based strategy $[24,41]$. Typically, IMNM is suspected in three different situations and requires autoantibody investigation.

First, the serological screening is mandatory in patients with sub-acute signs of myopathies without extra-muscular manifestations, corresponding to patients with severe proximal muscle weakness (onset within a few weeks), myalgia, dysphagia, and high creatine kinase (CK) level.

The second major interest of antibodies detection is to identify muscle autoimmune disease in patients with slowly progressive muscle signs mimicking muscular dystrophy [42-44].

Conversely, antibodies exhibit high specificity for IMNM diagnosis with no detection amongst muscular dystrophy patients defined by clinical, pathological and genetic features $[31,45]$.

Finally, presence of anti-HMGCR appears to be useful to delineate adverse events related to statin exposure from IMNM. Indeed, $10-20 \%$ of statin users experienced muscle symptoms; but, the majority of patients do not develop anti-HMGCR autoantibodies [40]. The specific presence of anti-HMGCR in this population helps to confirm the diagnosis of anti-HMGCR IMNM and impacts the therapeutic management [26]. It is necessary to test anti-HMGCR antibodies in patients without clear improvement of muscle symptoms (including CK level) after statin withdrawal [40]. 


\section{Autoantibodies and clinical phenotypes}

\subsection{Classical phenotype: the subacute form}

Anti-HMGCR and anti-SRP IMNM are muscle-specific autoimmune diseases with severe and disabling proximal muscle weakness and limited extramuscular involvement. The disease onset usually occurs between $40-60$ years; however, there is no age limit range, indeed, several paediatric cases have been reported; women are more frequently affected with the exception in case of statin-exposed patients [25,31,46-48]. In anti-SRP/HMGCR patients, severe muscle weakness is the hallmark clinical feature and the disease is rapidly progressive with an average time to maximum disability occurring within months [49]. Muscle involvement is characterized by proximal-predominant and symmetrical muscle weakness affecting mostly the legs $[48,50]$. Biologically, muscle necrosis is correlated to a very high level of CK in serum. The main myopathological characteristics are necrosis/regeneration pattern with diverse ranges of intensity, upregulation of class I major histocompatibility complex on the sarcolemma of regenerative muscle fibres with rarely a diffuse overexpression, scarce inflammatory infiltrate with mostly macrophages, and deposits of membrane attack complex on non-necrotic fibres $[25,31,51,52]$.

Even if anti-SRP and anti-HMGCR patients share clinical and biological features, some differences are underlined according to the antibody status (phenotypic comparison detailed in table).

Muscle damages are more severe in anti-SRP IMNM compared to anti-HMGCR [25]. AntiSRP patients specifically harbour axial muscle weakness $(70 \%)$ with $7 \%$ displaying a dropped head syndrome [10]. Dysphagia is also a frequent symptom (41\%). Comparison of permanent muscle damages between anti-SRP and anti-HMGCR patients by magnetic resonance imaging found more atrophy and fatty replacement in anti-SRP patients [53]. First descriptions of anti-SRP patients found a frequent signal with cardiac involvement that was balanced [27,54]. The frequency and the characteristic of cardiac involvement in anti-SRP 
patients remain to be clarified. The primary extramuscular symptoms is interstitial lung disease (13\%), and, non-specific systemic symptoms (rash, arthralgia, Raynaud's phenomenon...) are rarely present [10].

In comparison, Anti-HMGCR IMNM was described initially as an acute or subacute proximal muscle weakness. Few patients harboured extramuscular symptoms such as Raynaud's phenomenon. None of them presented related interstitial lung disease [15].

The first description of anti-HMGCR IMNM patients revealed $67 \%$ with statin exposure [4]. In a prospective Japanese cohort, only $18 \%$ of anti-HMGCR IMNM patients were under a medication regimen by statins [25]. Reported statin exposure rate vary widely in anti-HMGCR patients from $15 \%$ to $72.7 \%$ depending on the geographic origin and the median age of patients $[32,50,55]$. Meanwhile, the low prevalence of statin exposure in some regions might be compensated by an increased uptake of non-drug sources of statins (red yeast rice, fungus, dietary supplements...).

\subsection{Slowly progressive form}

Beside the subacute form of the disease, 20-30\% of IMNM patients exhibit a chronic slowly progressive myopathy [25,50]. This phenotype is also reported in paediatric case series of anti-SRP and anti-HMGCR IMNM [46,47,56,57].

Indeed, a subgroup of IMNM patients have a slow onset with muscle atrophy, sometimes scapula winging with dystrophic features (muscle fibres with asymmetric diameters, endomysium fibrosis and no muscular inflammation) in the muscle biopsy [42-44]. This phenotype is in accordance with limb girdle muscular disease $[21,58,59]$. It is crucial to isolate this subgroup of patients since treatments are available. Systematic screening is required in case of atypical context, manifestations or evolution to avoid misdiagnose.

4. Autoantibodies as therapeutic target 


\subsection{Standard of care}

Up to now, therapeutic strategies are based on expert opinion, data from case reports and analogy with other inflammatory idiopathic myopathies and/or autoimmune diseases [60]. The $224^{\text {th }}$ ENMC international workshop published a consensus for the initial treatment and some general principles about maintenance treatment [24]. High-dose steroids are described as the first treatment in combination with methotrexate (or azathioprine, mycophenolate mofetil) or rituximab and/or intravenous immunoglobulins (IVIg). Maintenance treatment is required for at least two years, the objective should be steroid tapering as soon as possible [24]. Even in the recommendations, strategies are slightly different according to antibody status, especially regarding IVIg use.

We reviewed available data on strategies targeting antibodies.

\subsection{Intravenous immunoglobulins}

IVIg are derived from the serum of thousands of donors pooled together. The mechanisms of action are still only partially understood and differ depending on the disease condition; some data suggest an anti-inflammatory and immunomodulatory role via fragment crystallizable (Fc) blockade, neutralization of complement proteins, and reduction of the IgG half-life by binding the Fc neonatal receptor [61]. IVIg in combination with other treatments have been regularly reported as efficacious in IMNM [60-63] but as mentioned above, no clinical trials have demonstrated their efficacy. Other case reports in anti-HMGCR suggest a positive effect of IVIg, including in paediatric patients [46,50]. Of note, one retrospective study demonstrated a significantly better clinical outcome in patients with early IVIg use within the first 3 months [66].

It has been shown that infusions of IVIg alone may improve muscle strength and CK levels in anti-HMGCR IMNM patients [67]. In our experience, it could be difficult, especially in antiHMGCR IMNM patients, to stop IVIg without having a relapse.

\subsection{Plasmapheresis}


Based on the potential direct pathogenic role of autoantibodies, plasmapheresis is conducted, usually as induction treatment in severe patients.

Limited data are available. First, it is shown that plasmapheresis induces a decrease of antiSRP antibodies levels in serum, then a rebound of antibodies levels was observed but with an inferior level compared to the first plasmapheresis [11]. Two cases of anti-SRP IMNM were treated by plasmapheresis and steroids inducing a remission [68]. Two cases of antiHMGCR patients were treated by first-line combination of steroids, methotrexate, IVIg and plasmapheresis. Rituximab replaced plasmapheresis and IVIg in one case. In the same series, three patients had treatment intensification with several combinations including plasmapheresis [50]. The only randomized control trial evaluating plasmapheresis was performed in cortico-resistant polymyositis and dermatomyositis and showed no substantial clinical improvement but we did not know if anti-SRP or anti-HMGCR positive patients were enrolled [69].

To date, there is no consensus about the role of plasmapheresis in the therapeutic strategy, but perhaps it should be discussed for use with very severely affected patients.

\subsection{Rituximab anti-CD20}

Rituximab is a chimeric anti-CD20 monoclonal antibody. CD20 is a B cell marker from pre-B stage to mature B cells. Rituximab has various therapeutic effects via complement-mediated cytotoxicity, antibody-dependent cell toxicity, and apoptosis by caspase activation. Only one open-label phase II trial in refractory anti-synthetase syndrome tested rituximab and had mild results [70]. Regarding IMNM patients, a case series of 8 anti-SRP patients demonstrated an improvement of muscle strength or CK levels in 6 patients with 3 of these patients having a sustained response and tapering of concomitant steroids [71]. Another cohort of anti-SRP patients $(n=39)$ confirmed these results with 13 responsive patients amongst 21 patients who received rituximab; 4 patients were non-responsive [47]. Data available for anti-HMGCR 
patients are scarce and in our experience Rituximab as a limited effect in refractory antiHMGCR patients (less than 30\%) $[57,65,72]$.

\subsection{Perspectives}

Interleukin 6 (IL-6) is a major cytokine with wide spectrum of activities. Amongst other functions, IL-6 induces inflammatory proteins synthesis, B cells differentiation into antibodyproducing plasma cells, and T follicular helper cells differentiation [73]. In rheumatoid arthritis patients, anti-IL-6 receptor treatment, tocilizumab, reduces $\mathrm{T}$ follicular helper cells and plasmablasts [74]. This treatment might be interesting to consider in IMNM; only two case of anti-Jo1 patients reported improvement under tocilizumab treatment [75].

Currently in the United States of America, a randomized clinical trial is ongoing to study tocilizumab in refractory inflammatory idiopathic myopathy patients including IMNM [76].

One anti-SRP patient achieved clinical remission under abatacept, the cytotoxic $\mathrm{T}$ lymphocyte-associated antigen-4-immunoglobulin fusion protein [77]. Abatacept suppresses T cell-dependent B cell response and seems to directly regulate B cells. Its efficacy has been proved in rheumatoid arthritis patients and a clinical trial is recruiting patients to investigate abatacept in inflammatory idiopathic myopathies including IMNM [78].

5. Autoantibodies as prognostic biomarker

\subsection{Long-term outcome}

The overall study of the long-term outcome of inflammatory idiopathic myopathy confirmed a poor outcome with increased mortality rate in patients compared to the general population [79]. In dermatomyositis, cancer risk and interstitial lung disease were the major determinant of mortality [79]. No such study has been realized specifically for IMNM patients, but their clinical evolution has been investigated. 
Several cohorts of anti-SRP positive patients described three types of clinical course. First, approximately one-third of the patients experienced favourable evolution under treatment. More than half of them required various immunosuppressant drugs and did not completely recover. Finally, approximately $10-20 \%$ had minimal to no response to therapy and developed progressive muscle weakness $[10,18,49]$.

Neurological outcome was found more severe in patients with early-onset IMNM. Young antiSRP patients harboured chronic disease progression, severe limbs and neck weakness, and muscle atrophy, and the younger age was the only independent factor of poor outcome in multivariate analysis [10]. At 4 years of disease onset, only $50 \%$ of anti-SRP patients recovered in term of muscle strength, and relapses were frequent and in parallel with treatment tapering [47]. For anti-HMGCR, muscle strength recovery was independently associated with patient age at disease onset. At 4-year follow-up, approximately $85 \%$ of patients age $>60$ years at disease onset recovered near normal muscle strength versus approximately $45 \%$ recovery in the subgroup with age $<53$ years [48].

These diseases are disabling due to permanent muscle damage and have a high impact on morbidity. After the 2-year follow-up under immunotherapy, one-third of anti-SRP patients had modified Rankin Scale scores of 3-5 underlying the high daily burden of the disease in their daily activities [47].

\subsection{Antibody titer and disease activity}

In clinical practice, disease activity of IMNM is followed by repeated elevated CK measurements in serum. Correlation between muscle necrosis and elevation of CK levels is very consistent $[17,47]$. CK evaluation is the gold standard in term of a prognosis biomarker. Several studies focused on evaluation of the antibody titer and disease activity.

Two different correlations were identified in IMNM patients. First, an inverted association between anti-SRP or anti-HMGCR antibody titers and muscle strength was observed $[11,32,50]$. In anti-HMGCR IMNM, no patient completely normalized his antibody titer 
independent of the muscle strength recovery or the medication regimen [55]. For anti-SRP IMNM, anti-SRP levels were not correlated to disease duration [11].

The second correlation was found between autoantibody titer and CK levels, especially at baseline $[11,17,30,32]$. During the disease course, change in CK levels may be difficult to identify due to the muscle atrophy and the fatty replacement. Disease activity evaluation may require magnetic resonance imaging follow-up. These correlations are also indirect argument suggesting a pathological role of autoantibodies.

To date, sufficient data are not available to recommend antibody titer as a surrogate marker of disease activity.

\subsection{Autoantibodies and cancer risk}

The increased risk of cancer in case of inflammatory idiopathic myopathy has been well documented especially in dermatomyositis patients with anti-TIF1y and NXP2 [80]. Historically, polymyositis patients had a higher risk of cancer [80].

A study focused on cancer risk in IMNM patients showed an increased risk of synchronous malignancy in patients with seronegative IMNM (21.4\%) and with anti-HMGCR IMNM (11.5\%) but not with anti-SRP IMNM (4\%). Moreover, compared to the cancer registry, incidence of cancer was enhanced especially in seronegative patients and to a lesser extent in anti-HMGCR patients [81]. This cancer association in anti-HMGCR patients has not been identified in every cohorts, and once identified, it was a mild risk predominantly in the older patients (> 50 years-old) $[48,81,82]$. Conversely, in a cohort of 100 patients, no cancer association was established in anti-SRP IMNM patients [18]. Anti-HMGCR IMNM patients with synchronous cancer had a higher rate of mortality compared to cancer-free anti-HMGCR patients [81,82].

Conclusion 
In inflammatory idiopathic myopathy, anti-SRP and anti-HMGCR autoantibodies delineate subgroups of patients in term of clinical, biological and histological phenotype. These diseases are muscle-specific autoimmune disease with very few extramuscular involvements. Currently, they are part of the diagnosis strategy as key criterion allowing for the postponement of a muscle biopsy. The correlation between antibody titer and disease activity, the pathological features, and the in vitro experiments results pointed toward a pathogenic effect of the autoantibodies. The recent in vivo experiments also strongly suggest this role.

Long-term outcome is highly impacted by major permanent muscle damages. Anti-SRP and anti-HMGCR patients harboured a poor recovery rate with frequent relapses. Multiple treatment lines are usually needed with a risk of high burden in term of adverse events. Improvement of treatment management is required, and antibodies appear to be an interesting target.

\section{Highlights}

Anti-HMGCR and anti-SRP antibodies are the cornerstone of IMNM diagnosis.

IMNM without autoantibody is associated with cancer risk.

Treatments target autoantibodies because of their potential direct pathogenic role.

\section{Bibliography}

[1] Hoogendijk JE, Amato AA, Lecky BR, Choy EH, Lundberg IE, Rose MR, et al. 119th ENMC international workshop: trial design in adult idiopathic inflammatory myopathies, with the exception of inclusion body myositis, 10-12 October 2003, Naarden, The Netherlands. Neuromuscul Disord NMD 2004;14:337-45. doi:10.1016/j.nmd.2004.02.006.

[2] Miller T, Al-Lozi M, Lopate G, Pestronk A. Myopathy with antibodies to the signal recognition particle: clinical and pathological features. J Neurol Neurosurg Psychiatry 2002;73:420-8. doi:10.1136/jnnp.73.4.420.

[3] Wang L, Liu L, Hao H, Gao F, Liu X, Wang Z, et al. Myopathy with anti-signal recognition particle antibodies: Clinical and histopathological features in Chinese patients. Neuromuscul Disord 2014;24:335-41. doi:10.1016/j.nmd.2014.01.002. 
[4] Mammen AL, Chung T, Christopher-Stine L, Rosen P, Rosen A, Doering KR, et al. Autoantibodies against 3-hydroxy-3-methylglutaryl-coenzyme A reductase in patients with statin-associated autoimmune myopathy. Arthritis Rheum 2011;63:713-21. doi:10.1002/art.30156.

[5] Mariampillai K, Granger B, Amelin D, Guiguet M, Hachulla E, Maurier F, et al. Development of a New Classification System for Idiopathic Inflammatory Myopathies Based on Clinical Manifestations and Myositis-Specific Autoantibodies. JAMA Neurol 2018. doi:10.1001/jamaneurol.2018.2598.

[6] Reeves WH, Nigam SK, Blobel G. Human autoantibodies reactive with the signal-recognition particle. Proc Natl Acad Sci U S A 1986;83:9507-11.

[7] Halic M, Becker T, Pool MR, Spahn CMT, Grassucci RA, Frank J, et al. Structure of the signal recognition particle interacting with the elongation-arrested ribosome. Nature 2004;427:80814. doi:10.1038/nature02342.

[8] Nagai K, Oubridge C, Kuglstatter A, Menichelli E, Isel C, Jovine L. NEW EMBO MEMBER'S REVIEW. EMBO J 2003;22:3479-85. doi:10.1093/emboj/cdg337.

[9] Römisch K, Miller FW, Dobberstein B, High S. Human autoantibodies against the 54 kDa protein of the signal recognition particle block function at multiple stages. Arthritis Res Ther 2006;8:R39. doi:10.1186/ar1895.

[10] Suzuki S, Nishikawa A, Kuwana M, Nishimura H, Watanabe Y, Nakahara J, et al. Inflammatory myopathy with anti-signal recognition particle antibodies: case series of 100 patients. Orphanet J Rare Dis 2015;10. doi:10.1186/s13023-015-0277-y.

[11] Benveniste O, Drouot L, Jouen F, Charuel J-L, Bloch-Queyrat C, Behin A, et al. Correlation of anti-signal recognition particle autoantibody levels with creatine kinase activity in patients with necrotizing myopathy. Arthritis Rheum 2011;63:1961-71. doi:10.1002/art.30344.

[12] Drouot L, Allenbach Y, Jouen F, Charuel J-L, Martinet J, Meyer A, et al. Exploring necrotizing autoimmune myopathies with a novel immunoassay for anti-3-hydroxy-3-methyl-glutaryl-CoA reductase autoantibodies. Arthritis Res Ther 2014;16:R39. doi:10.1186/ar4468.

[13] Friesen JA, Rodwell VW. The 3-hydroxy-3-methylglutaryl coenzyme-A (HMG-CoA) reductases. Genome Biol 2004;5:248. doi:10.1186/gb-2004-5-11-248.

[14] Istvan ES, Palnitkar M, Buchanan SK, Deisenhofer J. Crystal structure of the catalytic portion of human HMG-CoA reductase: insights into regulation of activity and catalysis. EMBO J 2000;19:819-30. doi:10.1093/emboj/19.5.819.

[15] Christopher-Stine L, Casciola-Rosen LA, Hong G, Chung T, Corse AM, Mammen AL. A novel autoantibody recognizing 200-kd and $100-k d$ proteins is associated with an immune-mediated necrotizing myopathy. Arthritis Rheum n.d.;62:2757-66. doi:10.1002/art.27572.

[16] Osaki Y, Nakagawa Y, Miyahara S, Iwasaki H, Ishii A, Matsuzaka T, et al. Skeletal muscle-specific HMG-CoA reductase knockout mice exhibit rhabdomyolysis: A model for statin-induced myopathy. Biochem Biophys Res Commun 2015;466:536-40. doi:10.1016/j.bbrc.2015.09.065.

[17] Allenbach Y, Arouche-Delaperche L, Preusse C, Radbruch H, Butler-Browne G, Champtiaux N, et al. Necrosis in anti-SRP+ and anti-HMGCR+myopathies: Role of autoantibodies and complement. Neurology 2018;90:e507-17. doi:10.1212/WNL.0000000000004923.

[18] Kao AH, Lacomis D, Lucas M, Fertig N, Oddis CV. Anti-signal recognition particle autoantibody in patients with and patients without idiopathic inflammatory myopathy. Arthritis Rheum 2004;50:209-15. doi:10.1002/art.11484.

[19] Arouche-Delaperche L, Allenbach Y, Amelin D, Preusse C, Mouly V, Mauhin W, et al. Pathogenic role of anti-signal recognition protein and anti-3-Hydroxy-3-methylglutaryl-CoA reductase antibodies in necrotizing myopathies: Myofiber atrophy and impairment of muscle regeneration in necrotizing autoimmune myopathies. Ann Neurol 2017;81:538-48. doi:10.1002/ana.24902.

[20] Rojana-udomsart A, Mitrpant C, Bundell C, Price L, Luo Y-B, Fabian V, et al. Complementmediated muscle cell lysis: A possible mechanism of myonecrosis in anti-SRP associated necrotizing myopathy (ASANM). J Neuroimmunol 2013;264:65-70.

doi:10.1016/j.jneuroim.2013.08.008. 
[21] Choi J-H, Park Y-E, Kim S-I, Kim J-I, Lee C-H, Park K-H, et al. Differential Immunohistological Features of Inflammatory Myopathies and Dysferlinopathy. J Korean Med Sci 2009;24:1015-23. doi:10.3346/jkms.2009.24.6.1015.

[22] Afzali AM, Ruck T, Wiendl H, Meuth SG. Animal models in idiopathic inflammatory myopathies: How to overcome a translational roadblock? Autoimmun Rev 2017;16:478-94. doi:10.1016/j.autrev.2017.03.001.

[23] Bergua C, Chiavelli H, Allenbach Y, Arouche-Delaperche L, Arnoult C, Bourdenet G, et al. In vivo pathogenicity of IgG from patients with anti-SRP or anti-HMGCR autoantibodies in immunemediated necrotising myopathy. Ann Rheum Dis 2018. doi:10.1136/annrheumdis-2018-213518.

[24] Allenbach $Y$, Mammen AL, Benveniste O, Stenzel W, Allenbach $Y$, Amato A, et al. 224th ENMC International Workshop:: Clinico-sero-pathological classification of immune-mediated necrotizing myopathies Zandvoort, The Netherlands, 14-16 October 2016. Neuromuscul Disord 2018;28:87-99. doi:10.1016/j.nmd.2017.09.016.

[25] Watanabe Y, Uruha A, Suzuki S, Nakahara J, Hamanaka K, Takayama K, et al. Clinical features and prognosis in anti-SRP and anti-HMGCR necrotising myopathy. J Neurol Neurosurg Psychiatry 2016;87:1038-44. doi:10.1136/jnnp-2016-313166.

[26] Shovman O, Gilburd B, Chayat C, Lazar AD, Amital H, Blank M, et al. Anti-HMGCR antibodies demonstrate high diagnostic value in the diagnosis of immune-mediated necrotizing myopathy following statin exposure. Immunol Res 2017;65:276-81. doi:10.1007/s12026-016-8867-x.

[27] Brouwer R, Hengstman GJD, Egberts WV, Ehrfeld H, Bozic B, Ghirardello A, et al. Autoantibody profiles in the sera of European patients with myositis. Ann Rheum Dis 2001;60:116-123.

[28] Hengstman GJD, Brouwer R, Egberts WTMV, Seelig HP, Jongen PJH, van Venrooij WJ, et al. Clinical and serological characteristics of 125 Dutch myositis patients. Myositis specific autoantibodies aid in the differential diagnosis of the idiopathic inflammatory myopathies. J Neurol 2002;249:69-75.

[29] Musset L, Allenbach Y, Benveniste O, Boyer O, Bossuyt X, Bentow C, et al. Anti-HMGCR antibodies as a biomarker for immune-mediated necrotizing myopathies: A history of statins and experience from a large international multi-center study. Autoimmun Rev 2016;15:983-93. doi:10.1016/j.autrev.2016.07.023.

[30] Aggarwal R, Oddis CV, Goudeau D, Fertig N, Metes I, Stephens C, et al. Anti-signal recognition particle autoantibody ELISA validation and clinical associations. Rheumatol Oxf Engl 2015;54:1194-9. doi:10.1093/rheumatology/keu436.

[31] Suzuki S, Yonekawa T, Kuwana M, Hayashi YK, Okazaki Y, Kawaguchi Y, et al. Clinical and histological findings associated with autoantibodies detected by RNA immunoprecipitation in inflammatory myopathies. J Neuroimmunol 2014;274:202-8. doi:10.1016/j.jneuroim.2014.07.006.

[32] Ge Y, Lu X, Peng Q, Shu X, Wang G. Clinical Characteristics of Anti-3-Hydroxy-3-Methylglutaryl Coenzyme A Reductase Antibodies in Chinese Patients with Idiopathic Inflammatory Myopathies. PLoS ONE 2015;10. doi:10.1371/journal.pone.0141616.

[33] Alshehri A, Choksi R, Bucelli R, Pestronk A. Myopathy with anti-HMGCR antibodies. Neurol Neuroimmunol Neuroinflammation 2015;2. doi:10.1212/NXI.0000000000000124.

[34] Malkan A, Cappelen-Smith C, Beran R, Griffith N, Toong C, Wang M-X, et al. Anti-synthetase syndrome associated with anti PL-12 and anti-Signal recognition particle antibodies and a necrotizing auto-immune myositis. J Clin Neurosci 2015;22:396-8. doi:10.1016/j.jocn.2014.04.031.

[35] Vincze M, Molnár PA, Tumpek J, Szőllősi L, Gyetvai Á, Kapitány A, et al. An unusual association: anti-Jo1 and anti-SRP antibodies in the serum of a patient with polymyositis. Clin Rheumatol 2010;29:811-4. doi:10.1007/s10067-010-1394-6.

[36] Jaskowski TD, La'ulu SL, Mahler M, Tebo AE. Detection of autoantibodies to 3-hydroxy-3methylglutaryl-coenzyme a reductase by ELISA in a reference laboratory setting. Clin Chim Acta 2017;472:30-4. doi:10.1016/j.cca.2017.07.011. 
[37] Musset L, Miyara M, Benveniste O, Charuel J-L, Shikhman A, Boyer O, et al. Analysis of Autoantibodies to 3-Hydroxy-3-methylglutaryl-coenzyme A Reductase Using Different Technologies. J Immunol Res 2014;2014. doi:10.1155/2014/405956.

[38] Alvarado-Cardenas M, Marin-Sánchez A, Martínez MA, Martínez-Martínez L, Pinal-Fernandez I, Labrador-Horrillo $\mathrm{M}$, et al. Statin-associated autoimmune myopathy: A distinct new IFL pattern can increase the rate of HMGCR antibody detection by clinical laboratories. Autoimmun Rev 2016;15:1161-6. doi:10.1016/j.autrev.2016.09.005.

[39] Palterer B, Cammelli D, Vitiello G, Giudizi MG. Anti-HMGCR and anti-DFS70 antibodies immunofluorescence patterns. Autoimmun Rev 2017;16:321-2. doi:10.1016/j.autrev.2017.01.002.

[40] Mammen AL, Pak K, Williams EK, Brisson D, Coresh J, Selvin E, et al. Rarity of anti-3-hydroxy-3methylglutaryl-coenzyme $A$ reductase antibodies in statin users, including those with selflimited musculoskeletal side effects. Arthritis Care Res n.d.;64:269-72. doi:10.1002/acr.20662.

[41] Suzuki S, Uruha A, Suzuki N, Nishino I. Integrated Diagnosis Project for Inflammatory Myopathies: An association between autoantibodies and muscle pathology. Autoimmun Rev 2017;16:693-700. doi:10.1016/j.autrev.2017.05.003.

[42] Ikeda K, Mori-Yoshimura M, Yamamoto T, Sonoo M, Suzuki S, Kondo Y, et al. Chronic Myopathy Associated With Anti-Signal Recognition Particle Antibodies Can Be Misdiagnosed As Facioscapulohumeral Muscular Dystrophy. J Clin Neuromuscul Dis 2016;17:197-206. doi:10.1097/CND.0000000000000115.

[43] Carvalho AA de S, da Silva VG, Zanoteli E, Feder D. Myopathy due to HMGCR antibodies in adult mimicking muscular dystrophy associated with cancer and statin exposure - narrative review of the literature - case report. Ther Clin Risk Manag 2018;14:903-7. doi:10.2147/TCRM.S162931.

[44] Mohassel P, Foley AR, Donkervoort S, Fequiere PR, Pak K, Bönnemann CG, et al. Anti-3-hydroxy3-methylglutaryl-coenzyme a reductase necrotizing myopathy masquerading as a muscular dystrophy in a child. Muscle Nerve 2017;56:1177-81. doi:10.1002/mus.25567.

[45] Mammen AL, Casciola-Rosen L, Christopher-Stine L, Lloyd TE, Wagner KR. Myositis-specific autoantibodies are specific for myositis compared to genetic muscle disease. Neurol Neuroimmunol Neuroinflammation 2015;2:e172. doi:10.1212/NXI.0000000000000172.

[46] Liang W-C, Uruha A, Suzuki S, Murakami N, Takeshita E, Chen W-Z, et al. Pediatric necrotizing myopathy associated with anti-3-hydroxy-3-methylglutaryl-coenzyme A reductase antibodies. Rheumatol Oxf Engl 2017;56:287-93. doi:10.1093/rheumatology/kew386.

[47] Pinal-Fernandez I, Parks C, Werner JL, Albayda J, Paik JJ, Danoff SK, et al. Longitudinal Course of Disease in a Large Cohort of Myositis Patients With Autoantibodies Recognizing the Signal Recognition Particle. Arthritis Care Res 2017;69:263-70. doi:10.1002/acr.22920.

[48] Tiniakou E, Pinal-Fernandez I, Lloyd TE, Albayda J, Paik J, Werner JL, et al. More severe disease and slower recovery in younger patients with anti-3-hydroxy-3-methylglutaryl-coenzyme $A$ reductase-associated autoimmune myopathy. Rheumatol Oxf Engl 2017;56:787-94. doi:10.1093/rheumatology/kew470.

[49] Hengstman GJD, ter Laak HJ, Egberts WTMV, Lundberg IE, Moutsopoulos HM, Vencovsky J, et al. Anti-signal recognition particle autoantibodies: marker of a necrotising myopathy. Ann Rheum Dis 2006;65:1635-8. doi:10.1136/ard.2006.052191.

[50] Allenbach Y, Drouot L, Rigolet A, Charuel JL, Jouen F, Romero NB, et al. Anti-HMGCR Autoantibodies in European Patients With Autoimmune Necrotizing Myopathies. Medicine (Baltimore) 2014;93. doi:10.1097/MD.0000000000000028.

[51] Suzuki S, Yonekawa T, Kuwana M, Hayashi YK, Okazaki Y, Kawaguchi Y, et al. Clinical and histological findings associated with autoantibodies detected by RNA immunoprecipitation in inflammatory myopathies. J Neuroimmunol 2014;274:202-8. doi:10.1016/j.jneuroim.2014.07.006.

[52] Preuße C, Goebel HH, Held J, Wengert O, Scheibe F, Irlbacher K, et al. Immune-Mediated Necrotizing Myopathy Is Characterized by a Specific Th1-M1 Polarized Immune Profile. Am J Pathol 2012;181:2161-71. doi:10.1016/j.ajpath.2012.08.033. 
[53] Pinal-Fernandez I, Casal-Dominguez M, Carrino JA, Lahouti AH, Basharat P, Albayda J, et al. Thigh muscle MRI in immune-mediated necrotising myopathy: extensive oedema, early muscle damage and role of anti-SRP autoantibodies as a marker of severity. Ann Rheum Dis 2017;76:681-7. doi:10.1136/annrheumdis-2016-210198.

[54] Targoff IN, Johnson AE, Miller FW. Antibody to signal recognition particle in polymyositis. Arthritis Rheum 1990;33:1361-70. doi:10.1002/art.1780330908.

[55] Werner JL, Christopher-Stine L, Ghazarian SR, Pak KS, Kus JE, Daya NR, et al. Antibody Levels Correlate with Creatine Kinase Levels and Strength in Anti-HMG-CoA Reductase-Associated Autoimmune Myopathy. Arthritis Rheum 2012;64:4087-93. doi:10.1002/art.34673.

[56] Rider LG, Shah M, Mamyrova G, Huber AM, Rice MM, Targoff IN, et al. The Myositis Autoantibody Phenotypes of the Juvenile Idiopathic Inflammatory Myopathies. Medicine (Baltimore) 2013;92:223-43. doi:10.1097/MD.0b013e31829d08f9.

[57] Tansley SL, Betteridge ZE, Simou S, Jacques TS, Pilkington C, Wood M, et al. Anti-HMGCR Autoantibodies in Juvenile Idiopathic Inflammatory Myopathies Identify a Rare but Clinically Important Subset of Patients. J Rheumatol 2017;44:488-92. doi:10.3899/jrheum.160871.

[58] Takahashi T, Aoki M, Suzuki N, Tateyama M, Yaginuma C, Sato H, et al. Clinical features and a mutation with late onset of limb girdle muscular dystrophy 2B. J Neurol Neurosurg Psychiatry 2013;84:433-40. doi:10.1136/jnnp-2011-301339.

[59] Nalini A, Gayathri N. Dysferlinopathy: a clinical and histopathological study of 28 patients from India. Neurol India 2008;56:379-85; discussion 386-387.

[60] Cavagna L, Monti S, Caporali R, Gatto M, laccarino L, Doria A. How I treat idiopathic patients with inflammatory myopathies in the clinical practice. Autoimmun Rev 2017;16:999-1007. doi:10.1016/j.autrev.2017.07.016.

[61] Lünemann JD, Nimmerjahn F, Dalakas MC. Intravenous immunoglobulin in neurology-mode of action and clinical efficacy. Nat Rev Neurol 2015;11:80-9. doi:10.1038/nrneurol.2014.253.

[62] Binns EL, Moraitis E, Maillard S, Tansley S, McHugh N, Jacques TS, et al. Effective induction therapy for anti-SRP associated myositis in childhood: A small case series and review of the literature. Pediatr Rheumatol Online J 2017;15. doi:10.1186/s12969-017-0205-x.

[63] Kusumoto T, Okamori S, Masuzawa K, Asakura T, Nishina N, Chubachi S, et al. Development of Necrotizing Myopathy Following Interstitial Lung Disease with Anti-signal Recognition Particle Antibody. Intern Med Tokyo Jpn 2018. doi:10.2169/internalmedicine.0303-17.

[64] Giudizi MG, Cammelli D, Vivarelli E, Biagiotti R, Ferraro A, Bentow C, et al. Anti-HMGCR antibody-associated necrotizing myopathy: diagnosis and treatment illustrated using a case report. Scand J Rheumatol 2016;45:427-9. doi:10.3109/03009742.2015.1132761.

[65] Ramanathan S, Langguth D, Hardy TA, Garg N, Bundell C, Rojana-Udomsart A, et al. Clinical course and treatment of anti-HMGCR antibody-associated necrotizing autoimmune myopathy. Neurol Neuroimmunol Neuroinflammation 2015;2. doi:10.1212/NXI.0000000000000096.

[66] Kassardjian CD, Lennon VA, Alfugham NB, Mahler M, Milone M. Clinical Features and Treatment Outcomes of Necrotizing Autoimmune Myopathy. JAMA Neurol 2015;72:996-1003. doi:10.1001/jamaneurol.2015.1207.

[67] Mammen AL, Tiniakou E. Intravenous Immune Globulin for Statin-Triggered Autoimmune Myopathy. N Engl J Med 2015;373:1680-2. doi:10.1056/NEJMc1506163.

[68] Arlet J-B, Dimitri D, Pagnoux C, Boyer O, Maisonobe T, Authier F-J, et al. Marked efficacy of a therapeutic strategy associating prednisone and plasma exchange followed by rituximab in two patients with refractory myopathy associated with antibodies to the signal recognition particle (SRP). Neuromuscul Disord NMD 2006;16:334-6. doi:10.1016/j.nmd.2006.03.002.

[69] Miller FW, Leitman SF, Cronin ME, Hicks JE, Leff RL, Wesley R, et al. Controlled Trial of Plasma Exchange and Leukapheresis in Polymyositis and Dermatomyositis. N Engl J Med 1992;326:1380-4. doi:10.1056/NEJM199205213262102.

[70] Allenbach Y, Guiguet M, Rigolet A, Marie I, Hachulla E, Drouot L, et al. Efficacy of Rituximab in Refractory Inflammatory Myopathies Associated with Anti- Synthetase Auto-Antibodies: An Open-Label, Phase II Trial. PloS One 2015;10:e0133702. doi:10.1371/journal.pone.0133702. 
[71] Valiyil R, Casciola-Rosen L, Hong G, Mammen A, Christopher-Stine L. Rituximab Therapy for Myopathy Associated with Anti-Signal Recognition Particle Antibodies: A Case Series. Arthritis Care Res 2010;62:1328-34. doi:10.1002/acr.20219.

[72] Landon-Cardinal O, Allenbach Y, Rigolet A, Simon A, Champtiaux N, Benveniste O. Rituximab for the treatment of anti-HMGCR necrotizing autoimmune myopathy. Neuromuscul Disord 2016;26:S144. doi:10.1016/j.nmd.2016.06.211.

[73] Tanaka T, Narazaki M, Kishimoto T. IL-6 in Inflammation, Immunity, and Disease. Cold Spring Harb Perspect Biol 2014;6. doi:10.1101/cshperspect.a016295.

[74] Chavele K-M, Merry E, Ehrenstein MR. Cutting edge: circulating plasmablasts induce the differentiation of human T follicular helper cells via IL-6 production. J Immunol Baltim Md 1950 2015;194:2482-5. doi:10.4049/jimmunol.1401190.

[75] Narazaki M, Hagihara K, Shima Y, Ogata A, Kishimoto T, Tanaka T. Therapeutic effect of tocilizumab on two patients with polymyositis. Rheumatol Oxf Engl 2011;50:1344-6. doi:10.1093/rheumatology/ker152.

[76] Tocilizumab in the Treatment of Refractory Polymyositis and Dermatomyositis - Full Text View ClinicalTrials.gov n.d. https://clinicaltrials.gov/ct2/show/NCT02043548 (accessed June 28, 2018).

[77] Maeshima K, Kiyonaga Y, Imada C, Iwakura M, Hamasaki H, Haranaka M, et al. Successful treatment of refractory anti-signal recognition particle myopathy using abatacept. Rheumatology 2014;53:379-80. doi:10.1093/rheumatology/ket251.

[78] Trial to Evaluate the Efficacy and Safety of Abatacept in Combination With Standard Therapy Compared to Standard Therapy Alone in Improving Disease Activity in Adults With Active Idiopathic Inflammatory Myopathy - Full Text View - ClinicalTrials.gov n.d. https://clinicaltrials.gov/ct2/show/NCT02971683 (accessed June 28, 2018).

[79] Dobloug GC, Svensson J, Lundberg IE, Holmqvist M. Mortality in idiopathic inflammatory myopathy: results from a Swedish nationwide population-based cohort study. Ann Rheum Dis 2018;77:40-7. doi:10.1136/annrheumdis-2017-211402.

[80] Zahr ZA, Baer AN. Malignancy in myositis. Curr Rheumatol Rep 2011;13:208-15. doi:10.1007/s11926-011-0169-7.

[81] Allenbach Y, Keraen J, Bouvier A, Jooste V, Champtiaux N, Hervier B, et al. High risk of cancer in autoimmune necrotizing myopathies: usefulness of myositis specific antibody. Brain 2016;139:2131-5. doi:10.1093/brain/aww054.

[82] Kadoya M, Hida A, Hashimoto Maeda M, Taira K, Ikenaga C, Uchio N, et al. Cancer association as a risk factor for anti-HMGCR antibody-positive myopathy. Neurol Neuroimmunol Neuroinflammation 2016;3. doi:10.1212/NXI.0000000000000290. 
Table: Phenotypic comparison between anti-HMGCR and anti-SRP immune-mediated necrotizing myositis

\begin{tabular}{|c|c|c|}
\hline & Anti-HMGCR IMNM & Anti-SRP IMNM \\
\hline \multicolumn{3}{|l|}{ Epidemiology } \\
\hline Age (median) & \multicolumn{2}{|c|}{$\begin{array}{l}\text { 40-60 years } \\
\text { No age limit }\end{array}$} \\
\hline Sex ratio & \multicolumn{2}{|c|}{ Female>Male } \\
\hline $\begin{array}{l}\text { Frequence of autoantibodies } \\
\text { amongst inflammatory idiopathic } \\
\text { myopathy patients }\end{array}$ & $\sim 6 \%$ & $4-13 \%$ \\
\hline $\begin{array}{l}\text { Frequence of autoantibodies } \\
\text { amongst IMNM patients }\end{array}$ & Up to $64 \%$ & Up to $53 \%$ \\
\hline Statins exposure & $15-70 \%$ & No association \\
\hline \multicolumn{3}{|l|}{ Phenotype } \\
\hline Muscle symptoms & $\begin{array}{l}\text { Proximal symmetric muscle } \\
\text { weakness } \\
\text { Muscle atrophy }\end{array}$ & $\begin{array}{l}\text { Proximal symmetric muscle weakness } \\
\text { (more severe) } \\
\text { Muscle atrophy (more frequent) } \\
\text { Axial muscle involvement/dropped head } \\
\text { syndrome }\end{array}$ \\
\hline Sub-acute/progressive form & \multicolumn{2}{|c|}{$2 / 3-1 / 3$} \\
\hline Dysphagia & $\sim 40 \%$ & $\sim 60 \%$ \\
\hline Extramuscular involvements & Very rare & $\begin{array}{l}10-20 \% \text { interstitial lung disease } \\
\text { Heart involvement }\end{array}$ \\
\hline Biomarker & \multicolumn{2}{|c|}{ Elevated CK level } \\
\hline
\end{tabular}




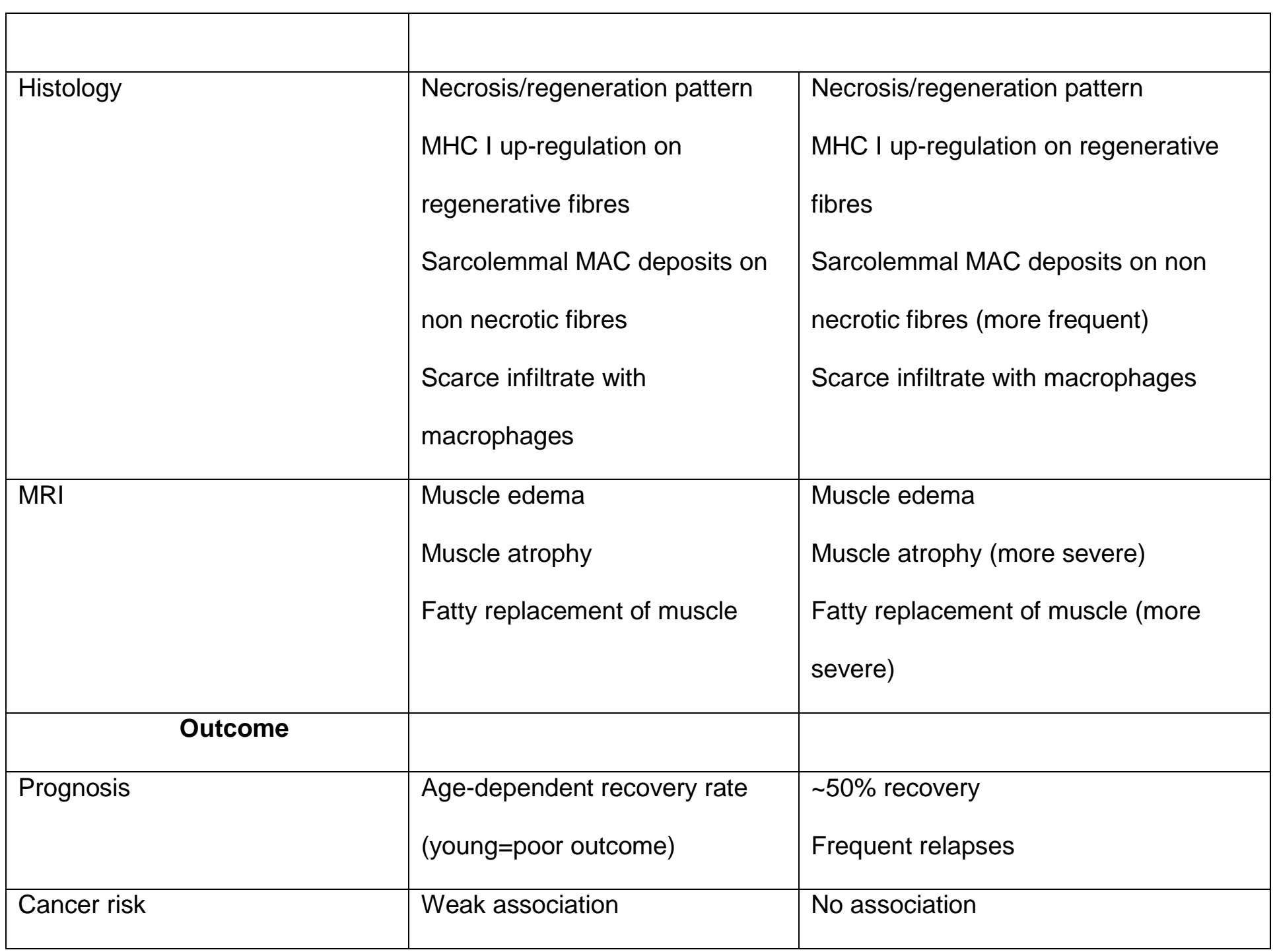

IMNM: immune-mediated necrotizing myopathy, anti-HMGCR: anti-3-Hydroxy-3-MethylGlutarylCoenzyme A Reductase, anti-SRP: anti-signal recognition particle, CK: creatine kinase, MHC: major histocompatibility complex, MAC: membrane attack complex (C5b-9), MRI: magnetic resonance imaging 
Figure: Clinical, biological and histological phenotype of Immune-mediated necrotizing myopathy

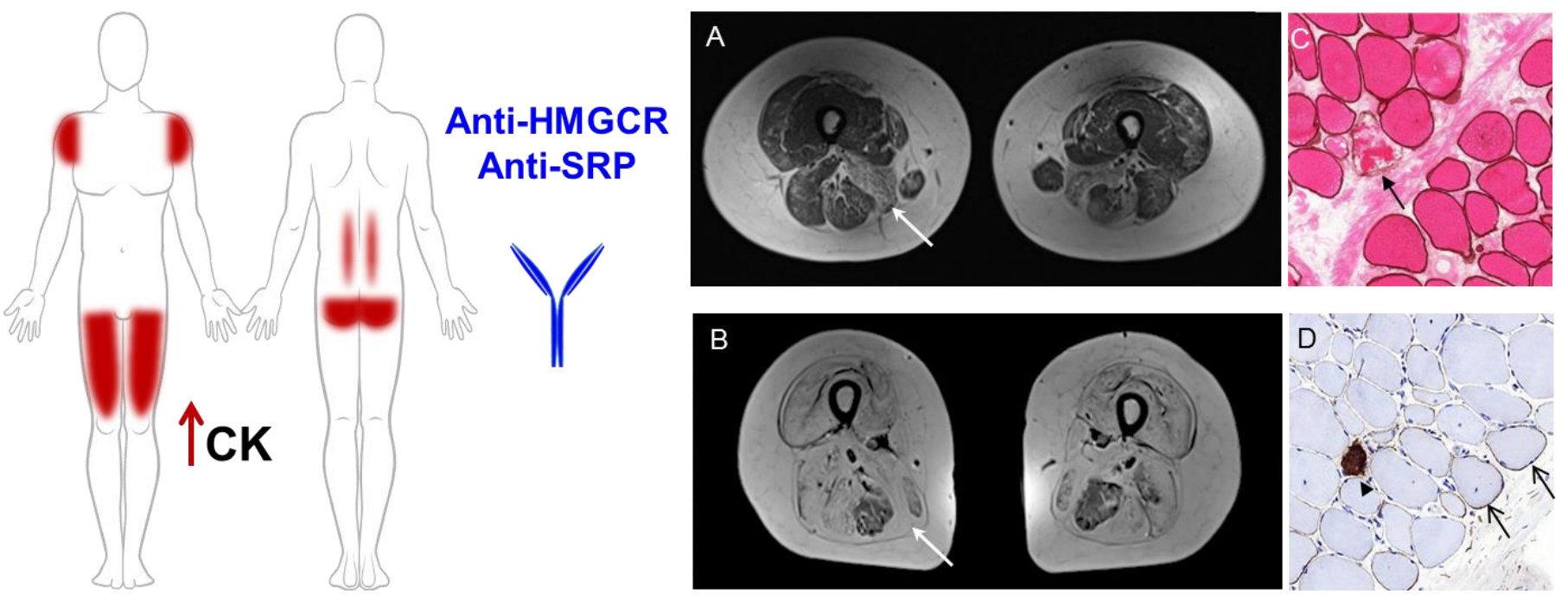

Anti-HMGCR: anti-3-Hydroxy-3-MethylGlutaryl-Coenzyme A Reductase, anti-SRP: anti-signal recognition particle, CK: creatine kinase, A) Magnetic Resonance Imaging image of anti-HMGCR patient with mild muscle damage B) Magnetic Resonance Imaging image of anti-SRP patient with very severe muscle damage with an almost complete fat replacement, A and B) white arrows: atrophy and fatty muscle replacements, C) Dystrophin immunostaining with eosin counterstaining. The arrow shows a necrotic fibre, D) C5b-9 immunostaining: the arrows show sarcolemmal C5b-9 deposits on non-necrotic fibres. Of note the arrowhead show a non-specific C5b-9 sarcoplasmic deposition on a necrotic fibre. 